\title{
The function of strategic tree selectivity in the chemical signalling of brown bears
}

\author{
Melanie Clapham ${ }^{\mathrm{a}}$, Owen T. Nevin ${ }^{\mathrm{b}}$, Andrew D. Ramsey ${ }^{\mathrm{a}}$, Frank Rosell ${ }^{\mathrm{c}, *}$ \\ ${ }^{a}$ Centre for Wildife Conservation, University of Cumbria, Penrith, U.K. \\ ${ }^{\mathrm{b}}$ CQUniversity, Gladstone, Australia \\ ${ }^{\mathrm{c}}$ Faculty of Art and Sciences, Department of Environmental and Health Studies, Telemark University College, Bø i Telemark, Norway
}

\section{A R T I C L E I N F O}

Article history:

Received 5 October 2012

Initial acceptance 4 December 2012

Final acceptance 8 March 2013

Available online 23 April 2013

MS, number: 12-00775

\section{Keywords:}

behavioural plasticity

brown bear

chemical communication

conspicuous object

energetic investment

rub tree

scent marking

Ursus arctos
Large mammals select conspicuous objects on which to deposit their scent marks, which may function to supplement the olfactory signal, visually and/or chemically. Analysing marking sites is paramount to understanding whether signallers could mitigate potential fitness costs by placing scents strategically to reduce time and energy investment. The defining characteristics of marking sites are unclear across species, and variation in the literature concerning selectivity may be explained by behavioural plasticity. We took an evolutionary perspective on the selection and spatial distribution of marking trees by brown bears, Ursus arctos, to account for such variation. Our hypothesis, that brown bears would be selective in the trees used for scent marking, was supported; the trees chosen were located in regularly visited areas, where the defence of a resource is needed. The criteria of a marking tree appear to be primarily location and then about properties that facilitate their use as a conspicuous object; bears selected rarer species and trees of larger size than the average available. Other features, such as aromatic properties of the species, bark texture and the ability of the bark to hold scent, may act additionally to determine a tree's marking potential. The energetic investment in manufacturing pungent volatile odours could be reduced if signallers utilize tree properties to attract receivers. Across mammalian taxa, whether a tree is selected for marking appears to vary based on environmental context; the principal function is to limit the energetic costs of producing scent marks by placing marks strategically to increase the likelihood of attracting potential receivers. (c) 2013 The Association for the Study of Animal Behaviour. Published by Elsevier Ltd. All rights reserved.
Chemical signalling is believed to have evolved throughout the animal kingdom because it allows a signaller to manipulate successfully the behaviour of receiving individuals to its own reproductive advantage (Dawkins \& Krebs 1978). Individuals benefit from selecting scent-marking strategies that increase their likelihood of detection, yet reduce the potential fitness cost to the signaller by mitigating time and energy investment (Gosling \& Roberts 2001). Scent marking on conspicuous trees and plants may function to supplement the olfactory signal, visually and/or chemically (Gorman \& Mills 1984; Bowyer et al. 1994; Rachlow 2001; Hayward \& Hayward 2010). Patterns of scent marking are seemingly related to the social dynamics of a species (Macdonald 1980). The marking patterns of nonterritorial mammals are less clear than those of territorial ones, and may display temporal and spatial variation, particularly in reference to defending mates and food resources (Gosling 1990). Artiodactyla and Carnivora select trees for marking depending on: the size and species of the tree; the slope of its trunk (henceforth referred to as 'the lean'); its bark texture; its aromatic properties; and

\footnotetext{
* Correspondence: F. Rosell, Faculty of Art and Sciences, Department of Environmental and Health Studies, Telemark University College, Bø i Telemark, Norway.

E-mail address: Frank.Rosell@hit.no (F. Rosell).
}

its conspicuousness in the environment (Kile \& Marchinton 1977; Benner \& Bowyer 1988; Smith et al. 1989; Bowyer et al. 1994; Bothma \& le Riche 1995; Massei \& Bowyer 1999; Ramos et al. 2006; Barja 2009; Nie et al. 2012; Piñeiro \& Barja 2012). Placing scent marks on trees may increase the visibility and dispersal of scent by increasing the elevation of the mark (Gorman \& Mills 1984; Alberts 1992), irrespective of the properties of the trees. The height of the scent mark on a tree could communicate size and therefore status of the animal (Alberts 1992). In addition, marking on the underside of a leaning tree may protect the scent mark from rainwater: a strategy selected by tigers, Panthera tigris (Smith et al.1989). Marking trees are probably chosen on the basis that they not only hold and disperse scent, but also act as an additional attractant (Kile \& Marchinton 1977; Bowyer et al. 1994); for example, marking trees are often located along major travel routes, where their likelihood of encounter by receivers is increased (Macdonald 1980). Variation in habitat could be used to explain intraspecific variation in spatial marking patterns (Smith et al. 1989). To bridge the gap between speculation and empirical data, we must begin to assess behaviours based on the social and spatial organization of species. Strategic tree selectivity for scent marking is likely to be influenced by a species' social behaviour, spatial structure and environment. 
Ursids mark trees in a similar way to other carnivores. Marking behaviours include rubbing various parts of the body against trees (to deposit scent from sebaceous and apocrine glands; reviewed in Müller-Schwarze 2006), clawing (possibly to deposit scent from pedal glands; reviewed in Sunquist \& Sunquist 2002), biting (possibly to deposit scent from salivary glands; as in Patterson 1968) and urinating and depositing anal gland secretions (AGS; Burst \& Pelton 1983; Schaller et al. 1985; Green \& Mattson 2003). Tree marking with modified cutaneous glands is reported to function in scent marking through the production of pheromones, with secretions under hormonal control (reviewed in Müller-Schwarze 2006; Johnston \& delBarco-Trillo 2009). Traditionally used trees are repeatedly marked over generations (Schaller et al. 1985), which indicates that scent marking functions as intraspecific communication in bears (Green \& Mattson 2003), rather than occurring in response to external environmental stimuli. However, the function behind the selection of these trees remains unclear. A limited number of authors have attempted to determine tree selectivity in ursids (see Burst \& Pelton 1983; Green \& Mattson 2003; Puchkovskiy 2009; Nie et al.2012), yet there is currently no consensus in the literature across the family Ursidae or the order Carnivora. Within the Ursidae, tree species (Puchkovskiy 2009), size (Green \& Mattson 2003) and bark texture (Nie et al. 2012) have each been reported to dictate selectivity. As ursids display highly adaptive social behaviour, predominantly exhibiting solitary living (Stirling \& Derocher 1990) but tolerating dense aggregations (Craighead et al. 1995), behavioural plasticity may explain variation within the literature on tree selectivity. However, the positioning of scent-marked trees appears to be consistent, being located on human-made/game trails, ridge tops and/or valley bottoms (Burst \& Pelton 1983; Schaller et al. 1985; Green \& Mattson 2003). Few studies analysing tree selectivity for marking within the Ursidae have considered it strategically, as a potential way to mitigate fitness costs to signallers.

In an attempt to decipher the principal function of tree selectivity for scent marking in large mammals, we took an evolutionary perspective; taking such a perspective may allow us to understand the inconsistent pattern of results across species reported in the literature, and may produce new indications of strategic decision making in a natural context. Using an ursid species as a case study, we investigated the selection and spatial distribution of marking trees in the brown bear, Ursus arctos. Assessing the selectivity of marking trees is paramount to understanding whether ursids could mitigate the potential fitness costs of chemical signalling by placing scents strategically. Other studies concerned with tree selection for marking by brown bears failed to construct hypotheses relating to the potential fitness costs/benefits of tree selectivity (Green \& Mattson 2003; Puchkovskiy 2009). Taking into account previous literature on ursids and other mammals (principally Artiodactyla), we hypothesized that brown bears would be selective in the trees used for marking; these should be located in regularly visited areas where the need to defend a resource is elevated. We predicted that brown bears would select trees that, through their properties, act as an additional attractant to receivers. If bears select trees based on species, we predicted that coniferous trees would be selected over broadleaved trees. If the size of the tree is important, we predicted that bears would select trees with a larger diameter than others in the area. These trees would probably have properties that facilitated their use as a conspicuous object on which to mark through their rarity.

\section{METHODS}

\section{Study Site}

Glendale Cove is an estuarine intertidal zone of Knight Inlet, British Columbia, Canada. The region is situated in the pacific mid- coast of the Province, and has a mild, hypermaritime climate because of its geographical location. The Pacific coast annually receives contributions of marine-derived nutrients from the remnants of five anadromous salmonid species (Oncorhynchus spp.), through their migration upstream, spawning and eventual decomposition. Approximately $40-50$ brown bears utilize the Glendale spawning channel as a primary energy resource during the autumn (Nevin 2003; Clapham et al. 2012).

Western hemlock, Tsuga heterophylla, is the dominant tree species in the area, interspersed with Western red cedar, Thuja plicata, amabilis fir, Abies amabilis, and Sitka spruce, Picea sitchensis (Alaback 1991). Deciduous species include red alder, Alnus rubra, and Pacific crabapple, Malus fusca, although these species are mainly concentrated at forest edges bordering the estuary. In the spring, approximately 20 brown bears are attracted to tidal marshes in the south of the estuary, to feed in the sedge meadows (Carex spp.; Clapham et al. 2012). This coincides with the breeding season, when adult males, lone adult females and courting pairs can often be seen in this area.

Data were collected from May to October 2009-2011. A combination of 13 fixed-distance tree transects, 16 game-trail tree transects and unsystematic random searches were conducted to assess how brown bears utilize their environment for chemical signalling. Methods used for identifying marking trees are outlined below, and were confirmed using 17 Reconyx (Reconyx Inc., Wisconsin, U.S.A.; models RC55 \& PC85) digital passive still-image infrared camera traps, which provided data for Clapham et al. (2012). Camera traps monitored 22 different brown bear marking trees throughout the study period, and were armed during the 'breeding season' (1 June-31 July in 2009/2010 and 15 April-31 July in 2011) and 'nonbreeding season' (1 August-5 October in 2010/2011; see Clapham et al. 2012 for camera trapping procedures).

\section{Analysis of Marking Trees and Tree Surveys}

\section{Identifying brown bear marking trees}

To distinguish a traditional marking tree from a tree that has merely been scratched or rubbed on a single occasion, we used the description of a black bear, $U$. americanus, marking tree set out by Burst \& Pelton (1983): one that has been bitten, clawed, and possibly rubbed, at the approximate height of a standing animal. This was confirmed for brown bear marking trees with camera traps and daily inspections of marking trees during the initial week of the study period. Trees must have displayed evidence of rubbing such as hair remnants, and visible claw and bite marks indicated through wounds on the tree. Scars caused by clawing and biting and the texture change of the bark caused by rubbing indicated that the tree was traditionally used. Only trees fitting this description were included in the analysis. Trees were not required to display evidence of recent marking to be included, as long as the features described above were visible. Fresh marks were identified by resin oozing from wounds, lacerated bark that left fragments exposed, the colour of exposed wood, and any remnants of hair loosely attached. Trees that showed the initial characteristics of a traditional marking tree but did not yet have the necessary evidence to be included were noted for further monitoring in following years, but not included in primary analysis. Camera traps provided corroborative evidence that marks left on trees were from brown bears and not black bears.

If a tree was identified as a marking tree, the species was recorded along with the diameter at breast height ( $\mathrm{dbh}$ ) using a dbh tape. The lean of the tree from $0^{\circ}$ was also recorded, using a clinometer. Features of the marks were recorded, including: height of the tallest visible mark from the base of the tree (unattainable in 
20 trees because of uncertainty in the maximum height of the mark); visual descriptions of the marks for identification purposes; and visual evidence of overmarking through differently aged marks. As multiple bears use the same trees for marking and some age-sex classes mark more than others (Clapham et al. 2012), marking tree data are not truly independent but are dictated by behavioural bias.

\section{Tree surveys}

Following the recording of data relating to the marking tree, we surveyed a sample area around the tree to consider the composition of trees on a local scale. All trees within a $5 \mathrm{~m}$ radius of the marking tree were recorded, noting species, dbh and lean of the tree $\left(^{\circ}\right)$ from vertical. When two marking trees were located within $10 \mathrm{~m}$ of each other, the more heavily used tree was recorded and a survey taken; the other tree was recorded but no surrounding tree survey was conducted, to avoid pseudoreplication of data. Marking trees identified during random searches of the forest as well as on systematic transects were also included in the analysis.

\section{Fixed Tree Transects}

Tree transects were used to assess the availability of different tree species in the area, to test for selectivity of trees for marking by brown bears. To assess the composition and diversity of trees within the landscape, 13 fixed-distance tree transects were conducted. Vegetation surveys consisted of $5 \times 200 \mathrm{~m}$ transects (total length $=2.6 \mathrm{~km}$ ), which began at the northwest corner of Glendale Cove estuary and were spaced $500 \mathrm{~m}$ apart leading south and ending on the eastern corner of the estuary. The number of transects was determined by the size of the study area (approximately $15 \mathrm{~km}^{2}$, including water) and the habitat diversity within the area. Each transect began where the tree line met the shoreline and ran $200 \mathrm{~m}$ perpendicular up the hillside. Effort was made to ensure as straight a line as possible was walked; however, safety hazards from the terrain or vegetation sometimes caused the line to vary slightly. All individual trees over $2 \mathrm{~m}$ in height within the defined area were identified to species level and recorded. Transect length was accurately measured throughout using a Walktax hipchain (Haglöf, Långsele, Sweden). We tried to ensure transects did not overlap and that the designated distance was maintained throughout. Transects were interrupted if a marking tree was encountered to collect the required data recorded.

\section{Trail Transects}

We conducted 16 transects (total length $=2.16 \mathrm{~km}$ ) following wildlife trails to assess the composition of trees on trails compared to the wider landscape (fixed tree transects). Trails were found by random searches beginning where the forest edge meets the shoreline. When approaching and departing the estuary, bears frequently use the same trails for ease of travel. We gained access to trails by using a disused logging road maintained by Knight Inlet Lodge. As with fixed transects, a hipchain counter was used from the start of each trail transect to calculate the length walked. Trail transects recorded all trees over $2 \mathrm{~m}$ in height, maintaining the $5 \mathrm{~m}$ width of previous fixed transects. Trail transects had a mean length of $135 \mathrm{~m}$ (range $61-219 \mathrm{~m}$ ). Trails were followed until the next direction could not be determined owing to the trail fading or, because trails are nonlinear, when they crossed roads, the intertidal zone, rivers or open sedge meadow. Transects measuring fewer than $50 \mathrm{~m}$ were not included in the analysis. Trail transects could begin in any location throughout the forest; however, we paid attention to the locations of recordings to avoid replication of sampling. Transects were permitted to cross one another; however, we avoided recording trails parallel to prerecorded transects.

\section{Data Analysis}

Chi-square goodness-of-fit tests were applied to transect data to compare the frequency of different species of tree randomly distributed in the landscape (fixed transects), parallel to game trails (trail transects) and around marking trees (tree surveys). Chisquare tests were then subdivided to assess the significance level between each observed and expected frequency. Post hoc subdivision of individual tests does not represent a repeated reanalysis of the data set with the associated risk of Type I error (Zar 1996; Nevin \& Gilbert 2005). Results were displayed as percentages but all data were tested as frequency values.

Multiple logistic regression analysis was conducted on marking tree data and local tree surveys to assess whether the species, size or lean of the tree contributed to a marking response (Zar 1996). A backwards-stepwise (conditional) method was selected for regression analysis to result in only significant values displayed in the end equation/model. An independent samples $t$ test was used to test for differences in the size of trees that were marked and those that were not. A Mann-Whitney $U$ test was used to discern whether the lean of a tree alone affected whether a tree was marked or not. A one-way analysis of variance (ANOVA) was used to assess whether dbh was primarily determined by tree species.

\section{RESULTS}

\section{Location of Marking Trees}

All documented marking trees were located at forest edges bordering the Glendale estuary and river drainage. These trees were clustered in locations close to productive food resources, such as estuary sedge in the spring and a salmon spawning river in the fall. Searches throughout the surrounding hillside revealed trees that showed some marking activity. However, these trees were much more widely spaced than those surrounding the estuary and did not display sufficient activity to be classed as traditional marking trees.

\section{Tree Selection for Marking}

All marking trees documented were encountered on game trails and not randomly distributed in the landscape. Two out of 50 marking trees were encountered on fixed transects; the rest were encountered during trail transects or random searches. Heavily marked trees were usually situated on more frequently used trails. Fixed and trail transects covered a similar total length $(2.6 \mathrm{~km}$ and $2.2 \mathrm{~km}$, respectively), yet there was a significant difference between the tree species encountered during these transects $\left(\chi_{5}^{2}=130.11\right.$, $P<0.001$; Fig. 1). Significantly more Western red cedar $(P<0.001)$ and red alder $(P<0.001)$, and significantly fewer Sitka spruce $(P=0.001)$ and Pacific crabapple $(P<0.001)$ trees were encountered during fixed transects than trail transects.

There was a significant difference between the availability of different tree species encountered on landscape-scale fixed transects, and those during tree surveys in the local vicinity of marking trees $\left(\chi_{4}^{2}=66.992, P<0.001\right.$; Fig. 2$)$. The selection of tree species for marking on a landscape scale was nonrandom $\left(\chi_{4}^{2}=227.664\right.$, $P<0.001$; Fig. 3a); amabilis fir $(P<0.001)$, Sitka spruce $(P<0.001)$ and Western red cedar $(P=0.009)$ were all marked significantly more than expected, Western hemlock was marked significantly less than expected $(P<0.001)$ and red alder as expected $(P=0.08)$. The selection of marking trees on a local scale was also nonrandom 


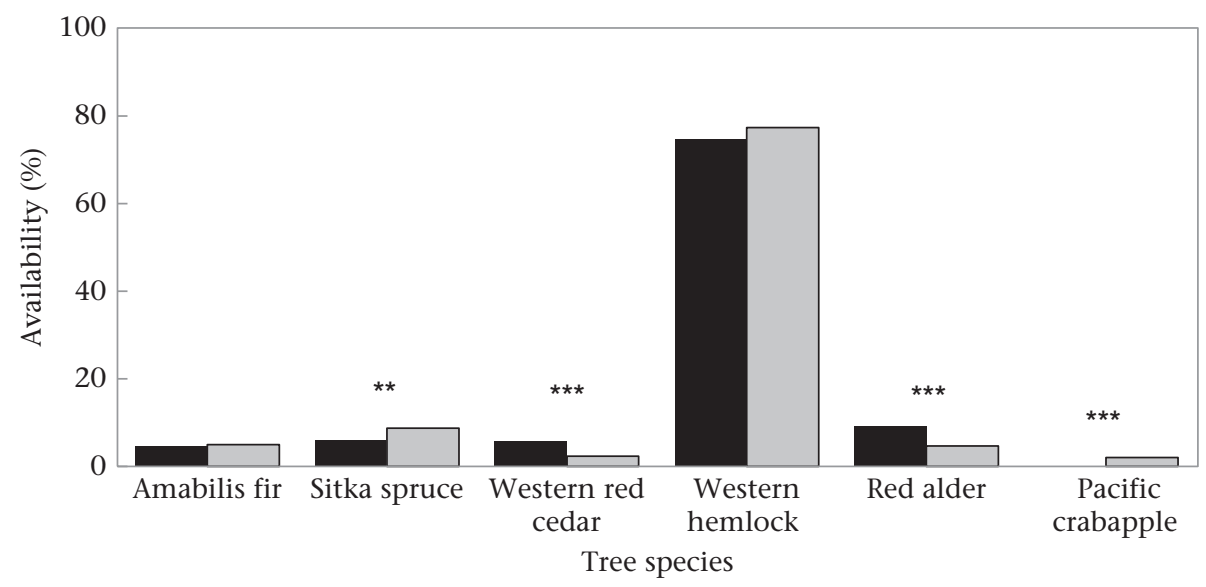

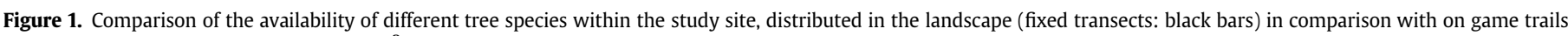
(trail transects: grey bars). ${ }^{* * *} P<0.001$ in $\chi^{2}$ subdivided testing; ${ }^{* *} P<0.01$.

$\left(\chi_{4}^{2}=152.712, P<0.001\right.$; Fig. $\left.3 \mathrm{~b}\right)$; amabilis fir $(P<0.001)$ and Western red cedar $(P=0.017)$ were selected significantly more than expected, Western hemlock $(P<0.001)$ significantly less, and Sitka spruce $(P=0.096)$ and red alder $(P=0.109)$ were both selected in proportion to their availability.

\section{Description of Marking Trees (Quantitative)}

Of the 50 marking trees documented: 23 were amabilis fir, 11 were Sitka spruce, eight were Western hemlock, seven were Western red cedar and one was red alder. Marking trees had a significantly larger dbh (mean $\pm \mathrm{SD}=42.52 \pm 21.24 \mathrm{~cm}$ ) than trees that were not marked in the local vicinity $(31.72 \pm 18.97 \mathrm{~cm}$; twotailed independent samples $t$ test: $\left.t_{302}=3.607, P<0.001\right)$. No significant difference was found in the lean of trees that were marked $\left(4.83 \pm 6.38^{\circ}\right)$ and those that were not in the local vicinity $\left(5.78 \pm 6.99 ; \quad\right.$ Mann-Whitney $U$ test: $U=4929.00, \quad N_{1}=47$ $\left.N_{2}=247, P=0.098\right)$. The mean of the maximum height of the mark on 30 marking trees was $2.02 \pm 0.22 \mathrm{~m}$. Investigation into the defining characteristics of marking trees through multiple logistic regression found that the likelihood of a tree being marked depended on its species (multiple logistic regression: $B=-1.092$, $\mathrm{SE}=0.155$, Wald $\left.\chi_{1}^{2}=49.825, P<0.001\right)$ and size $(B=0.21$, S.E. $=0.009$, Wald $\left.\chi_{1}^{2}=5.729, P=0.017\right)$. The full model, which considered all three independent variables together, was statistically significant (chi-square goodness-of-fit test: $\chi_{3}^{2}=72.135, P=<0.001$ ), indicating that the independent variables as a set reliably distinguish between marked and unmarked trees. The model correctly classified $87.4 \%$ of all cases. The dbh of marking trees was not influenced by species (ANOVA: $F_{4,45}=1.367$, $P=0.261)$; nor was the dbh of all trees documented at a local scale $\left(F_{4,299}=2.061, P=0.086\right)$.

\section{Description of Marking Trees (Qualitative)}

Marking trees displayed both old and fresh signs of marking. Dead trees that were active marking trees while alive were also occasionally marked when dead, although these are difficult to identify visually owing to the lack of fresh identifying marks. The appearance of fresh marks also varied temporally; marks caused by a bear rubbing on a tree with a wet pelage were generally visible for less than $2 \mathrm{~h}$ (Supplementary Material: Fig. S1a), whereas marks caused by biting or clawing the tree stayed fresh throughout the current year (Supplementary Material: Fig. S1b).

The appearance of marks also varied depending on the tree species itself. Amabilis fir and Sitka spruce trees often had large sections of bark removed by biting or clawing, leaving scars (Supplementary Material: Fig. S1c and d, respectively). In contrast, Western red cedar and Western hemlock typically did not display such scars (Western red cedar: Supplementary Material: Fig. S1g).

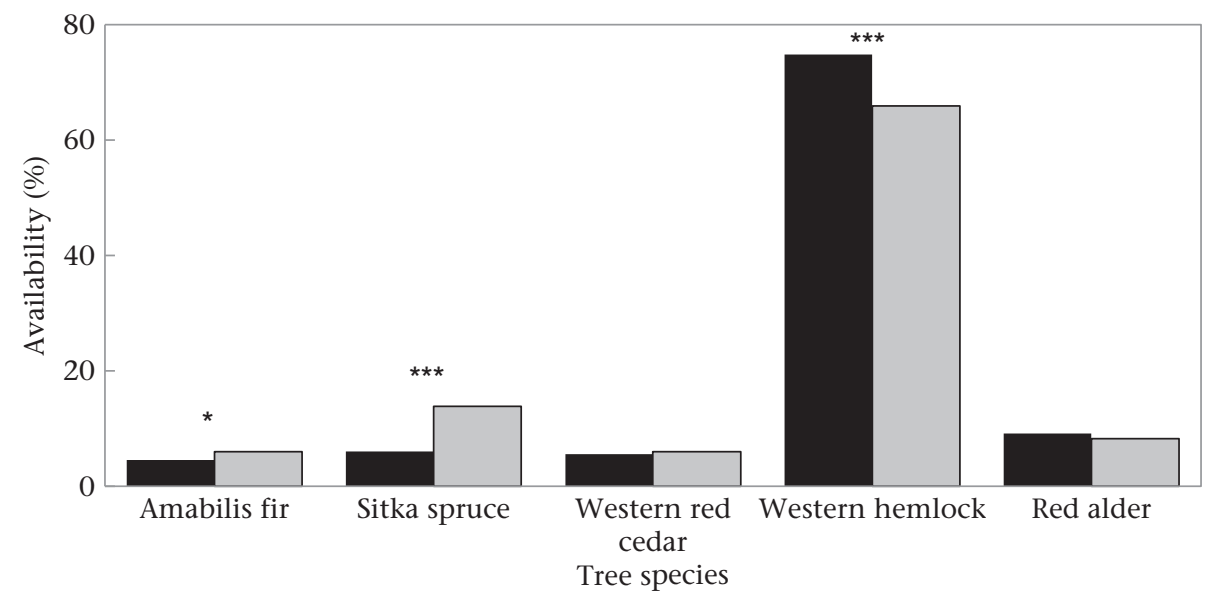

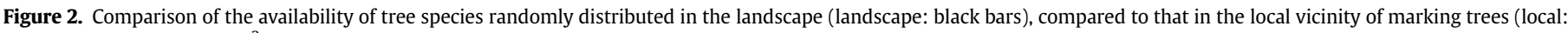
grey bars). ${ }^{* * *} P<0.001$ in $\chi^{2}$ subdivided testing; ${ }^{*} P<0.05$. 


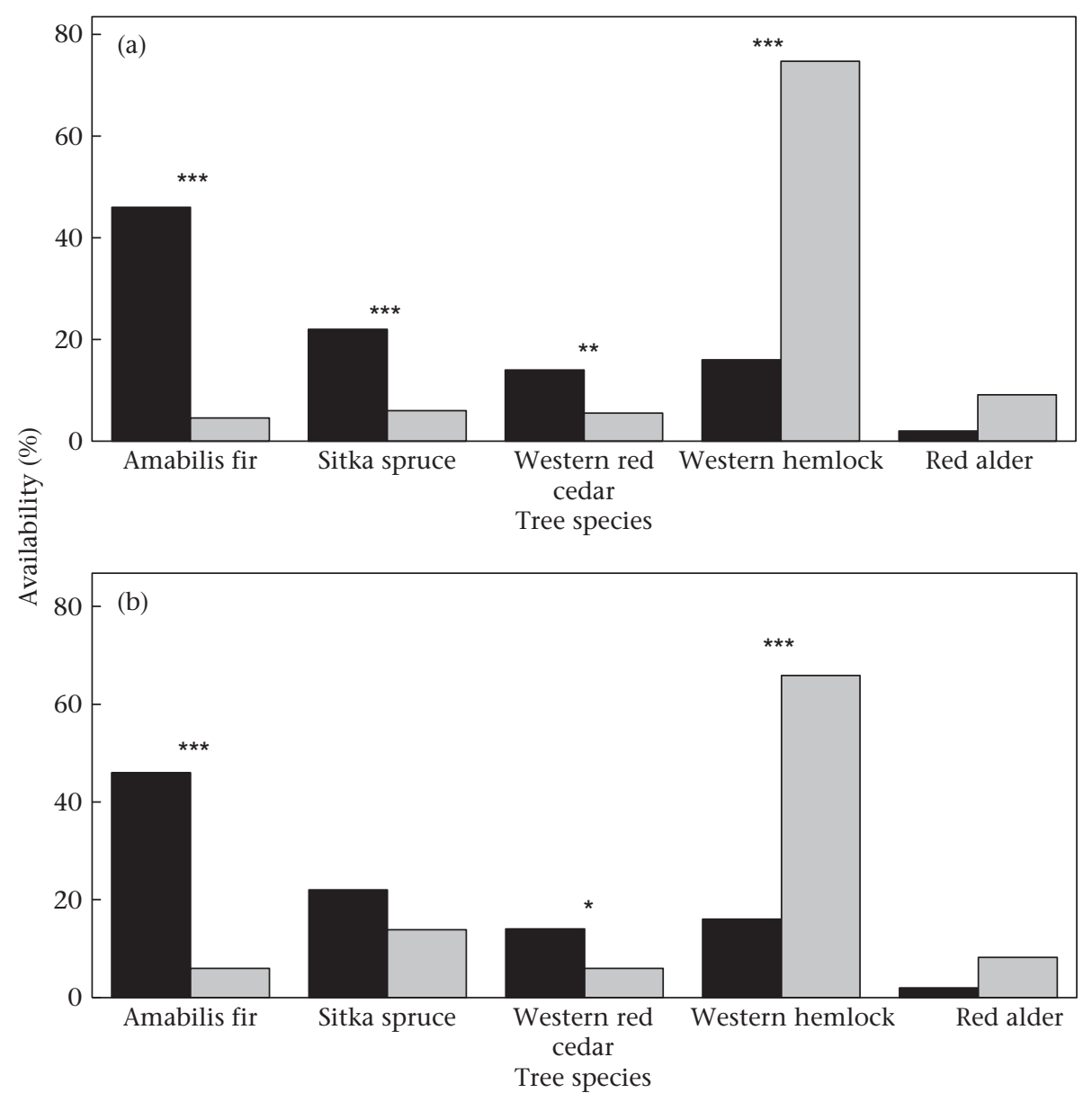

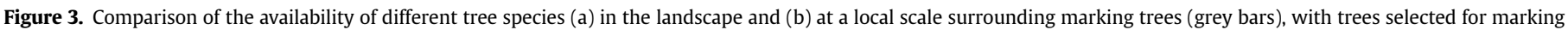
by bears (black bars). ${ }^{* * *} P<0.001$ in $\chi^{2}$ subdivided testing; ${ }^{* *} P<0.01 ;{ }^{*} P<0.05$.

The bark of these trees was rubbed down and the texture was different from areas that had not been rubbed (Western red cedar: Supplementary Material: Fig. S1e). Marking trees generally had no lower branches, although this was also typical of other trees within the forest that had not been marked.

The only broadleaved hardwood tree species found to be marked was red alder. Only one red alder tree was documented as a traditional marking tree. Marks on red alder trees appeared to be similar to those on Western red cedar and Western hemlock, in that rubbing seemed to be more prevalent than biting or clawing on the trees. Rubbing by bears darkened the appearance of red alder bark, as the bark texture is smooth originally (Supplementary Material: Fig. S1f).

Several marking trees had a series of depressions in the ground leading to them, caused by bears grinding and stomping their pads in succession (Supplementary Material: Fig. S1h); some were permanent and visible over the whole study period, and some only lasted one season. When stomping behaviour was observed directly, it was often noted that no visible or lasting marks on the ground remained, depending on the substrate (M. Clapham, personal observation). Therefore trees that did not have a noticeable trail to the human eye may still have had connected stomp trails.

\section{DISCUSSION}

Strategic surface selection for scent marking was investigated in brown bears to assess this type of decision making within the context of a natural environment. This study is the first to assess the selectivity of marking trees in brown bears, focusing on the mitigation of time and energy expenditure in relation to the potential fitness costs of signallers. Scent marking by brown bears met all the predictions generated based on previous studies across the Mammalia in relation to tree selectivity. The hypothesis that bears would be selective in the trees they used for marking, these being located in regularly visited areas, was supported. Results support the prediction that bears select trees that act as an additional attractant; bears selected rarer species and trees of larger size than the average available. Brown bears selected trees with properties that facilitated their use as a conspicuous object on which to mark.

Brown bears in the Glendale study area appear to select trees for marking based on their location, species and size, although location appears to be paramount. Large mammals usually select conspicuous, frequently used locations such as roadsides, game trails, dried riverbeds and intersections of these areas to deposit their scent marks (Sunquist 1981; Schaller et al. 1985; Gorman \& Trowbridge 1989). Brown bear marking trees within the Glendale drainage were located on game trails surrounding the estuary and river system, with patterns of use dictated by temporal food availability in the surrounding area (Clapham et al. 2012). Rogers (1987) suggested that the location of these trees seems to be known to bears, inferred by their unhesitant, routine-like manner of approach. Nonterritorial solitary species would gain from selecting a marking strategy that would increase the likelihood of detection by conspecifics, yet reduce the time and energy expenditure to the signaller (Gosling 1982). To facilitate the function of chemical signals in influencing the behaviour of receivers (Dawkins \& Krebs 
1978; Gosling 1981), scent marks should be in predetermined areas, where the defence of a resource is needed (Gosling 1990) as a result of conspecific pressure being greatest in these areas (Smith et al. 1989). If we consider females as a resource, as Gosling (1990) suggested, or more functionally the ability to mate as a resource worth defending, marks should be placed in areas frequented by females, and to which other males will be attracted (Emlen \& Oring 1977). Within the Glendale drainage, females are attracted to tidal marshes in the spring to feed on sedge, and males pursue females in these areas (Clapham et al. 2012). The location of marking trees along trails may simply be the result of their use of trails for movement; however, if marking location was a result of movement within the forest, we would also expect to find marking trees on the hillside, where bears preferentially dig daybeds (Mollohan 1987). Alternatively, their clustering around food resources and increased use on heavily used trails suggests strategic placement of scent marks. A conspicuous scent-marking location is therefore a prerequisite to efficient and effective chemical signalling. When a bear is in an area appropriate for a scent mark to be placed (i.e. a travel route near a resource such as food or a mate), it may then be selective as to which tree it marks.

Tree species composition within the study area varied according to whether the transect/tree survey was conducted at the valley bottom or on the hillside, and may have been dictated by an open canopy and changes in species availability at forest edges (see Pojar \& MacKinnon 1994). Conducting analysis not just on the trees selected, but also on those available in the landscape, showed that brown bears do not select trees in accordance with their availability, be this their species or size. This finding is consistent with the work of: Kile \& Marchinton (1977) and Nielsen et al. (1982) for white-tailed deer, Odocoileus virginianus; Smith et al. (1989) for tigers; Bowyer et al. (1994) for Alaskan moose, Alces alces; Bowyer et al. (1998) for American bison, Bison bison; Barja (2009) for Iberian wolves, Canis lupus; Nie et al. (2012) for giant pandas, Ailuropoda melanoleuca; and Piñeiro \& Barja (2012) for European wildcats, Felis silvestris. It therefore represents a strategy seen in species across five different mammalian families and two orders. Similarities across taxa may relate to such species being largely forest dwelling and solitary except during breeding, emphasizing the importance of environment and social system in scent-marking strategies. The strategy of selecting rarer species or trees of unusual size may account for intraspecific variation in the literature on tree selectivity for marking.

Brown bears selected trees to mark on in a species-specific manner. Certain properties of a tree, such as aromatic properties of the species, bark texture and its ability to hold scent, may determine its marking potential (Schaller et al. 1985; Nie et al. 2012). Frequently marked species, amabilis fir and Sitka spruce, both exude pungent resin when lacerated (M. Clapham, personal observations), which may contribute to the longevity of the chemical signal (see Alberts 1992); less frequently marked species, Western hemlock and red alder, produce little resin when lacerated. Alternatively, pungent aromas released from trees could act as an additional attractant to receivers by indicating that the tree has been modified and thereby increasing the likelihood of signal detection, a similar strategy to that adopted by some cervids (Kile \& Marchinton 1977; Bowyer et al. 1994). Hayward \& Hayward (2010) made the similar suggestion that black-backed jackals, Canis mesomelas, use the faecal latrines of other species to increase detectability of their own scent marks. As long-lasting pungent odours are expensive to make in energetic terms (Hurst et al. 1998; Gosling et al. 2000), we speculate that signallers may reduce their energetic expenditure by selecting aromatic trees on which to mark. Conversely, this could explain why smaller carnivores with strong-smelling odours, such as mustelids and large rodents (Gorman 1980; Macdonald 1980, 1985; Rosell \& Nolet 1997), select objects such as rocks or mounds for the deposition of their scent marks. Brown bears may also use aromatic trees as a novel odour for 'scent rubbing' (see Gosling \& McKay 1990).

Another important attribute of a marking tree is its size. In the study area brown bears favoured larger trees than were typical of the landscape on which to mark, irrespective of tree species. Some felids place scent marks on the underside of leaning trees, supposedly to protect the scent mark from rainwater (Smith et al. 1989). No evidence was found here to suggest that lean is an important feature of a marking tree for brown bears. Instead, brown bears appear to mark on the side of a tree parallel to the trail, irrespective of the orientation of the lean, where the likelihood of conspecifics encountering the scent is increased. Nie et al. (2012) also found that giant pandas selected trees that were closer to trails on which to mark.

It has been suggested that the height of a scent mark on a tree may constitute a visual signal to conspecifics: the higher the mark the bigger/fitter/older the bear (e.g. Alberts 1992). Data from this study show that for brown bears there is little variation in the total height of marks. Traditional marking trees by definition display a collection of marks from many different marking events. The height of the mark is unlikely to be a primary signalling strategy for brown bears, as cubs have been seen to climb trees and mark at a higher level (M. Clapham, personal observations), opening up this method of marking to cheating (Penn 2006), and some marking activities do not include bipedal back rubbing (Clapham 2012). However, scentmarking postures may have become ritualized to convey a signal; for example, giant panda handstand marks are thought to signal competitive ability and possibly aggressive intent between males (Swaisgood et al. 2000; White et al. 2002).

One of the defining advantages of scent marks is that they persist in the environment in the absence of the signaller. The longer a scent is able to persist, the less time and energy is invested in re-marking. By selecting to scent mark on a conspicuous object that is placed along well-used travel routes by conspecifics, brown bears are increasing the likelihood their scent mark will be encountered quickly and, more functionally, increasing the likelihood they will be able to manipulate receivers. Trees are often selected as a conspicuous object for marking; however, their selection is based on context. In forested landscapes, trees are not conspicuous unless they differ from their surroundings. Selection may then be dependent on the varying properties that attract receivers to the tree, through visual or olfactory capabilities. Whether trees are selected on the basis of species, size, aroma or signal persistence potential is likely to depend on the selective pressures and ecological circumstances faced by different scent-marking species; this may help to explain the variation in findings across species that have been documented in the literature. The central function is to limit the energetic costs of producing scent marks by placing marks strategically to increase the likelihood of attracting potential receivers. In this respect, variation in scent-marking strategies should be viewed as a response to environmental context, rather than a change in behavioural function.

\section{Acknowledgments}

This research was funded by the University of Cumbria, England and Knight Inlet Lodge, British Columbia, Canada. F.R. was funded by Telemark University College, Norway. We thank Dean and Kathy Wyatt and all the staff at Knight Inlet Lodge for continued field support and assistance. We are grateful to Morris Gosling, Volker Deecke and three anonymous referees for their comments and suggestions regarding this manuscript. 


\section{Supplementary Material}

Supplementary material associated with this article can be found, in the online version, at http://dx.doi.org/10.1016/j.anbehav. 2013.03.026.

\section{References}

Alaback, P. B. 1991. Comparative ecology of temperate rainforests of the Americas along analogous climatic gradients. Revista Chilena de Historia Natural (Santiago), 64, 399-412.

Alberts, A. C. 1992. Constraints on the design of chemical communication systems in terrestrial vertebrates. American Naturalist, 139, S62-S89.

Barja, I. 2009. Decision making in plant selection during the faecal-marking behaviour of wild wolves. Animal Behaviour, 77, 489-493.

Benner, J. M. \& Bowyer, R. T. 1988. Selection of trees for rubs by while-tailed deer in Maine. Journal of Mammalogy, 69, 624-627.

Bothma, J. \& le Riche, E. A. N. 1995. Evidence of the use of rubbing, scent-marking and scratching-posts by Kalahari leopards. Journal of Arid Environments, 29, 511-517.

Bowyer, R. T., Ballenberghe, V. V. \& Rock, K. R. 1994. Scent marking by Alaskan moose: characteristics and spatial distribution of rubbed trees. Canadian Journal of Zoology, 72, 2186-2192.

Bowyer, R. T., Manteca, X. \& Hoymork, A. 1998. Scent marking in American bison: morphological and spatial characteristics of wallows and rubbed trees. In: International Symposium on Bison Ecology and Management in North America (Ed. by L. R. Irby \& J. E. Knight), pp. 81-91. Bozeman, Montana: Montana State University.

Burst, T. L. \& Pelton, M. R. 1983. Black bear marks trees in the Smokey Mountains International Conference for Bear Research and Management, 5, 45-53.

Clapham, M. 2012. Chemical signalling in brown bears Ursus arctos: an assessment of scent marking strategies and social function. Ph.D. thesis, Lancaste University.

Clapham, M., Nevin, O. T., Ramsey, A. D. \& Rosell, F. 2012. A hypothetico-deductive approach to assessing the social function of chemical signalling in a nonterritorial solitary carnivore. PLoS One, 7, e35404.

Craighead, J. J., Sumner, J. S. \& Mitchell, J. A. 1995. The Grizzly Bears of Yellowstone: Their Ecology in the Yellowstone Ecosystem, 1959-1992. Washington DC: Island Press.

Dawkins, R. \& Krebs, J. R. 1978. Animal signals: information or manipulation? In: Behavioural Ecology: an Evolutionary Approach (Ed. by J. R. Krebs \& N. B. Davies) pp. 282-309. Oxford: Blackwell Scientific Publications.

Emlen, S. T. \& Oring, L. W. 1977. Ecology, sexual selection, and the evolution of mating systems. Science, 197, 215-223.

Gorman, M. L. 1980. Sweaty mongooses and other smelly carnivores. In: Symposium of the Zoological Society of London (Ed. by D. M. Stoddart), pp. 87-105. London: Academic Press.

Gorman, M. L. \& Mills, M. G. L. 1984. Scent marking strategies in hyaenas (Mammalia). Journal of Zoology, 202, 535-547.

Gorman, M. L. \& Trowbridge, B. J. 1989. The role of odour in the social lives of carnivores. In: Carnivore Behavior, Ecology and Evolution, Vol. 1 (Ed. by J. L. Gittleman), pp. 57-88. New York: Cornell University Press.

Gosling, L. M. 1981. Demarkation in a gerenuk territory: an economic approach. Zeitschrift für Tierpsychologie, 56, 305-322.

Gosling, L. M. 1982. A reassessment of the function of scent marking in territories. Zeitschrift fur Tierpsychologie, 60, 89-118.

Gosling, L. M. 1990. Scent marking by resource holders: alternative mechanisms for advertising the costs of competition. In: Chemical Signals in Vertebrates 5 (Ed. by D. W. Macdonald, D. Müller-Schwarze \& S. E. Natynczuk), pp. 315-328. Oxford Oxford University Press.

Gosling, L. M. \& McKay, H. V. 1990. Scent-rubbing and status signalling by male mammals. Chemoecology, 1, 92-95.

Gosling, L. M., Roberts, S. C., Thornton, E. A. \& Andrew, M. J. 2000. Life history costs of olfactory status signalling in mice. Behavioral Ecology and Sociobiology, 48, 328-332.

Gosling, L. M. \& Roberts, S. C. 2001. Scent-marking by male mammals: cheat-proof signals to competitors and mates. In: Advances in the Study of Behavior, Vol. 30 (Ed. by P. J. B. Slater, J. S. Rosenblatt, C. T. Snowdon \& T. J. Roper), pp. 169-218. San Diego: Academic Press.

Green, G. I. \& Mattson, D. J. 2003. Tree rubbing by Yellowstone grizzly bears Ursus arctos. Wildlife Biology, 9, 1-9.

Hayward, M. W. \& Hayward, G. J. 2010. Potential amplification of territorial advertisement markings by black-backed jackals (Canis mesomelas). Behaviour, 147, 979-992.

Hurst, J. L., Robertson, D. H. L., Tolladay, U. \& Beynon, R. J. 1998. Proteins in urine scent marks of male house mice extend the longevity of olfactory signals. Animal Behaviour, 55, 1289-1297.
Johnston, R. E. \& delBarco-Trillo, J. 2009. Communication by chemical signals: behavior, social recognition, hormones and the role of the vomeronasal and olfactory systems. In: Hormones, Brain and Behavior (Ed. by Donald W. Pfaff, Arthur P. Arnold, Susan E. Fahrbach, Anne M. Etgen \& Robert T. Rubin), pp. 395440. San Diego, California: Academic Press.

Kile, T. L. \& Marchinton, R. L. 1977. White-tailed deer rubs and scrapes: spatial, temporal and physical characteristics and social role. American Midland Naturalist, 97, 257-266.

Macdonald, D. W. 1980. Patterns of scent marking with urine and faeces amongst carnivore communities. In: Olfaction in Mammals. Symposium of the Zoological Society of London, No. 45 (Ed. by D. M. Stoddart), pp. 107-139. London: Academic Press.

Macdonald, D. W. 1985. The carnivores: order Carnivora. In: Social Odours in Mammals (Ed. by R. E. Brown \& D. W. Macdonald), pp. 619-722. New York: Oxford University Press.

Massei, G. \& Bowyer, R. T. 1999. Scent marking in fallow deer: effects of lekking behavior on rubbing and wallowing. Journal of Mammalogy, 80, 633-638.

Mollohan, C. M. 1987. Characteristics of adult female black bear daybeds in Northern Arizona. International Conference on Bear Research and Management, 7, 145-149.

Müller-Schwarze, D. 2006. Chemical Ecology of Vertebrates. New York: Cambridge University Press.

Nevin, 0. T. 2003. The influence of prey abundance and risk-sensitive behavioral change on individual access to high-energy food (salmon): impacts on the density and viability of bear populations. Ph.D. thesis, Utah State University.

Nevin, O. T. \& Gilbert, B. K. 2005. Perceived risk, displacement and refuging in brown bears: positive impacts of ecotourism? Biological Conservation, 121 $611-622$.

Nie, Y., Swaisgood, R. R., Zhang, Z., Hu, Y., Ma, Y. \& Wei, F. 2012. Giant panda scent-marking strategies in the wild: role of season, sex and marking surface. Animal Behaviour, 84, 39-44.

Nielsen, D. G., Dunlap, M. J. \& Miller, K. V. 1982. Pre-rut rubbing by white-tailed bucks: nursery damage, social role, and management options. Wildlife Society Bulletin, 10, 341-348.

Patterson, R. L. S. 1968. Identification of $3 \alpha$-hydroxy-5 $\alpha$-androst-16-ene as the musk odour component of boar submaxillary salivary gland and its relationship to the sex odour taint in pork meat. Journal of the Science of Food and Agriculture, 19, 434-438.

Penn, D. J. 2006. Chemical communication: five major challenges in the postgenomics age. In: Chemical Ecology: From Gene to Ecosystem (Ed. by M. Dicke \& W. Takken), pp. 9-18. Houten: Springer.

Piñeiro, A. \& Barja, I. 2012. The plant physical features selected by wildcats as signal posts: an economic approach to fecal marking. Naturwissenschaften, $\mathbf{9 9}$ 801-809.

Pojar, J. \& MacKinnon, A. 1994. Plants of the Pacific Northwest Coast: Washington, Oregon, British Columbia \& Alaska. Vancouver, British Columbia: Lone Pine Publishing.

Puchkovskiy, S. 2009. Selectivity of tree species as activity target of brown bear in Taiga. Contemporary Problems of Ecology, 2, 260-268.

Rachlow, J. L. 2001. Tree rubbing by white rhinos: potential functions of an undescribed behavior. Alces, 37, 447-456.

Ramos, J. A., Bugalho, M. N., Cortez, P. \& Iason, G. R. 2006. Selection of trees for rubbing by red and roe deer in forest plantations. Forest Ecology and Management, 222, 39-45.

Rogers, L. L. 1987. Effects of food supply and kinship on social behavior, movements, and population growth of black bears in northeastern Minnesota. Wildlife Monographs, 97, 3-72.

Rosell, F. \& Nolet, B. A. 1997. Factors affecting scent-marking behavior in Eurasian beaver (Castor fiber). Journal of Chemical Ecology, 23, 673-689.

Schaller, G. B., Jinchu, H., Wenshi, P. \& Jing, Z. 1985. The Giant Pandas of Wolong. Chicago: University of Chicago Press.

Smith, J. L. D., McDougal, C. \& Miquelle, D. 1989. Scent marking in free-ranging tigers, Panthera tigris. Animal Behaviour, 37, 1-10.

Stirling, I. \& Derocher, A. E. 1990. Factors affecting the evolution and behavioral ecology of the modern bears. Bears: Their Biology and Management, 8, 189-204.

Sunquist, M. E. 1981. The Social Organisation of Tigers (Panthera tigris) in Royal Chitawan National Park, Nepal. Washington DC: Smithsonian Institution Press.

Sunquist, M. E. \& Sunquist, F. 2002. Olfactory communication in felids. In: Wild Cats of the World (Ed. by M. E. Sunquist \& F. Sunquist), pp. 413-420. Chicago: University of Chicago Press.

Swaisgood, R. R., Lindburg, D. G., Zhou, X. \& Owen, M. A. 2000. The effects of sex, reproductive condition and context on discrimination of conspecific odours by giant pandas. Animal Behaviour, 60, 227-237.

White, A., Swaisgood, R. \& Zhang, H. 2002. The highs and lows of chemical communication in giant pandas (Ailuropoda melanoleuca): effect of scent deposition height on signal discrimination. Behavioral Ecology and Sociobiology, 51, 519-529.

Zar, J. H. 1996. Biostatistical Analysis. 3rd edn. Upper Saddle River, New Jersey: Prentice Hall. 